\title{
Does shared decision making respect a patient's relational autonomy?
}

\author{
Jonathan Lewis PhD, MA, MA (Cantab), Dr (D)
}

Institute of Ethics, Dublin City University, Dublin, Ireland

\section{Correspondence}

Jonathan Lewis, Faculty of Humanities and Social Sciences, Institute of Ethics, Dublin City University, S103 Senior House, All Hallows Campus, Dublin 9, Ireland.

Email: jonathan.lewis@dcu.ie

\begin{abstract}
According to many of its proponents, shared decision making ("SDM") is the right way to interpret the clinician-patient relationship because it respects patient autonomy in decision-making contexts. In particular, medical ethicists have claimed that SDM respects a patient's relational autonomy understood as a capacity that depends upon, and can only be sustained by, interpersonal relationships as well as broader health care and social conditions. This paper challenges that claim. By considering two primary approaches to relational autonomy, this paper argues that standard accounts of SDM actually undermine patient autonomy. It also provides an overview of the obligations generated by the principle of respect for relational autonomy that have not been captured in standard accounts of SDM and which are necessary to ensure consistency between clinical practice and respect for patient autonomy.
\end{abstract}

\section{KEYWORDS}

consent, medical decisions, recognition, relational autonomy, shared decision making, sovereignty

\section{1 | INTRODUCTION}

A systematic review by Makoul and Clayman has shown that there is a certain amount of consensus regarding the "essential conditions" of shared decision making ("SDM") practices. Specifically, SDM involves a description of the nature of the medical problem with physicians offering treatment options and describing probable benefits and potential harms. Accordingly, patients are required to understand and reflect on the information provided by the physician and, in return, they should communicate their values and preferences. Taking into account the evidence provided by the patient, physicians are required to present recommendations before the decision is executed. ${ }^{1}$ For the purposes of this paper, I will refer to this as a standard account of SDM.

A number of medical ethicists and medical researchers have argued that SDM is the right way to interpret the clinician-patient relationship because it respects patient autonomy in decision-making contexts. ${ }^{2-4}$ As James F. Childress has pointed out, bioethical accounts of autonomy have been dominated by the notion of "self-governance." In clinical decision-making contexts, this takes the form of a capacity to make decisions for oneself based on one's own values, desires, and motives. ${ }^{5}$ According to John Christman, traditional approaches to the capacity for self-governance, having posited procedural criteria for personal autonomy, are bound up with the notion of individuality. ${ }^{6}$ In terms of clinical decision making, it is generally accepted that patients must be competent such that they have the capacity to understand, retain, and internally reflect on information relating to a specific decision. $^{7-9}$ Patients must also fulfil authenticity conditions, which are employed to ensure procedural independence and to stress the selfendorsing nature of personal autonomy. ${ }^{6}$ Traditional theories inspired by the work of Harry Frankfurt tend to suggest that an individual has satisfied the conditions for authenticity if the values, desires, and motives that inform their decision have been self-endorsed through a procedure of internal, critical reflection. In general, an individual would not be procedurally independent with respect to their values, desires, and motives if their endorsement of them had resulted from self-deception, manipulation, or coercion.

In both contemporary philosophy and medical ethics, the conception of the procedurally independent, internally reflective, and selfendorsing agent has been challenged. Revisionary approaches have developed the idea that if there is such a thing as a self-governing agent, then that agent, and their associated capacity for autonomy, 
must be viewed as fundamentally and irreducibly relational. ${ }^{10-13}$ Proponents of SDM have also distanced themselves from more individualistic approaches to autonomy, arguing that the purpose of SDM is not only to inform patients about viable options and encourage patients to achieve informed preferences, but to respect a capacity of autonomy that is mutually dependent on interpersonal relationships as well as broader health care and social conditions. ${ }^{4,14}$ For example, van Nistelrooij et al have argued that the process of SDM "cannot dismiss the patient's relationality, but needs to seek a way to consider what these relations mean for the patient's identity and hence for his or her decision" (p. 643). ${ }^{15}$ Furthermore, this richer account of respect for autonomy has been affirmed by those who argue that SDM has been clinically motivated, in part, by the perception that it not only respects patient autonomy, but promotes it. Peter Ubel, for example, claims that patient empowerment is an essential feature of SDM. ${ }^{16}$ Elsewhere, Lisa Dive has suggested that SDM calls for processes that enhance a patient's capacity to be autonomous. ${ }^{17}$ In order to justify claims such as these, proponents of SDM have invoked relational conceptions of autonomy. ${ }^{15-18}$

Even though there may be other reasons that justify the requirements detailed in standard accounts of SDM, perhaps epistemic reasons and/or reasons concerning the quality of patient experiences, health outcomes, risk, and legislation, ${ }^{3,4,19,20}$ one of the challenges facing health practitioners and policymakers is the implementation of an account of SDM that is consistent with the principle of respect for patient autonomy. In this respect, the problem is that standard accounts of the requirements of SDM do not do justice to the principle of respect for relational autonomy. Following an overview of two primary approaches to relational autonomy-procedural and substantive-this paper articulates the conflict that, in principle, exists between extant standard accounts of SDM and the principle of respect for relational autonomy. As well as detailing the tensions, the paper offers an overview of the obligations generated by respect for relational autonomy that have not been captured by standard accounts of SDM.

\section{2 | A SKETCH OF RELATIONAL AUTONOMY IN MEDICAL ETHICS}

It has been claimed that individualistic accounts of autonomy in medical ethics reduce the patient-physician relationship to another form of paternalism. ${ }^{5}$ Such accounts not only demand that the physician remain neutral when it comes to patient preferences but also imply that the physician's role is merely to facilitate the provision of medically pertinent information. It has been suggested that such conditions lead to patients feeling neglected. ${ }^{4,5,14}$ By contrast, expressivist and pragmatic accounts of real discursive practices explain how an individual's ability to exercise their normative authority in making decisions requires a dynamic structure of recognition between discursive partners. ${ }^{21-23}$ The point is that a single individual cannot determine whether their decision is appropriate or correct. According to such accounts, the appropriateness of an individual's decision can only be understood in light of the particular norms built into, and dependent upon, our shared discursive practices. It follows that an individual's commitments, and the decisions that express those commitments, are made in the eyes of others. ${ }^{24}$ It is the responsibility of discursive partners to recognize what the individual is committed to in order to determine whether it is, in fact, appropriate or correct. On the basis of this expressivist and pragmatic approach, clinical decision making involves patients and physicians holding one another to account in $a$ recognitive game of commitment making, a game that is made explicit by articulating decisions and giving reasons for such decisions. It follows that exercises of one's autonomy in clinical decisions depends upon, and can only be sustained by, relations of interpersonal recognition. ${ }^{25}$ What emerges is a conception of autonomy that, as relational theorists claim, takes into account the fact that our practical identities, the values, desires, and motives that inform our decisions and the decisions themselves are shaped in and by the broader context of interpersonal, social relationships. ${ }^{26-29}$

In general, relational approaches to autonomy can be categorized either procedurally or substantively. Procedural approaches invoke both competency and authenticity conditions as necessary for autonomy. If a patient's commitments, and the claims that express those commitments, are competent and authentic, then their decisions should be respected. Proceduralists still, to a degree, affirm the model of the reflective, self-endorsing individual. However, due to the fact the one's decisions depend upon, and can only be sustained by, relations of interpersonal recognition, proceduralists have moved away from characterizing competency and authenticity exclusively in terms of individual reflection, endorsement, and decision.

According to substantive accounts of autonomy, "moral constraints are included in the articulation of autonomy either implicitly or explicitly" (p. 234). ${ }^{30}$ Depending on the specific approach one adopts, an individual's social relations must be normatively acceptable and not constitutive of subordination, subservience, and deference. ${ }^{31}$ Furthermore, the individual must commit to certain substantive ideals such as independence, egalitarianism, and/or ownership. ${ }^{25,30-32}$ A physician should recognize and respect a patient's decisions if and only if the latter satisfies these sorts of conditions. ${ }^{33}$ No matter whether the patient considers themselves to be able to exercise their autonomy or whether their physician considers them to have normative authority, the patient who fails to meet these conditions is unable to genuinely exercise their relational autonomy. ${ }^{33}$ On that basis, one could conclude that there is no autonomy-based obligation to allow them to make a decision about what treatment they will or will not receive. This conclusion, however, is undermined by the fact that, in the context of real clinical decisions, respect for relational autonomy cannot be considered independently of patient consent. Even if a patient fails to satisfy the conditions for relational autonomy (in either a procedural or a substantive sense), to treat them without their consent is inconsistent with their rightful authority to permit or refuse a treatment.

Just as a physician should respect the decisions of patients who satisfy the necessary conditions of relational autonomy, the patient's right to permit or refuse a particular treatment can also be grounded 
on the principle of respect for autonomy. However, it cannot be captured by the principle of respect for relational autonomy. Instead, it invokes a patient's "legal capacity" the basis of which is a sphere of autonomy referred to as the patient's sovereignty. ${ }^{34,35}$ Unlike relational autonomy, sovereignty is a juristic concept supported by the tort of battery. ${ }^{34,36}$ It follows that there is a distinction between a legal capacity approach to autonomy and the relational capacity for selfgovernance. ${ }^{37,38}$ The former concerns a patient's right to permit or refuse treatment and is consistent with settled legal principle, specifically, the principle that lawful reason is required before it is permissible to breach a person's bodily integrity (p. 405). ${ }^{39}$ Although respect for a patient's relational autonomy cannot be considered apart from their sovereignty-based legal capacity (Figure 1), violations of a patient's sovereignty are wrong for a different reason; specifically, such violations are considered in law to be trespasses upon the body of that person without consent as opposed to specific interferences that affect a patient's relational capacity to make decisions (p. 27). ${ }^{36}$

\section{I DOES SDM RESPECT PROCEDURAL APPROACHES TO RELATIONAL AUTONOMY?}

This section seeks to determine the extent to which standard accounts of SDM respect a patient's relational autonomy when it is conceived procedurally. To recap, Makoul and Clayman claim that, in SDM, physicians should offer options, describe their effectiveness, probable
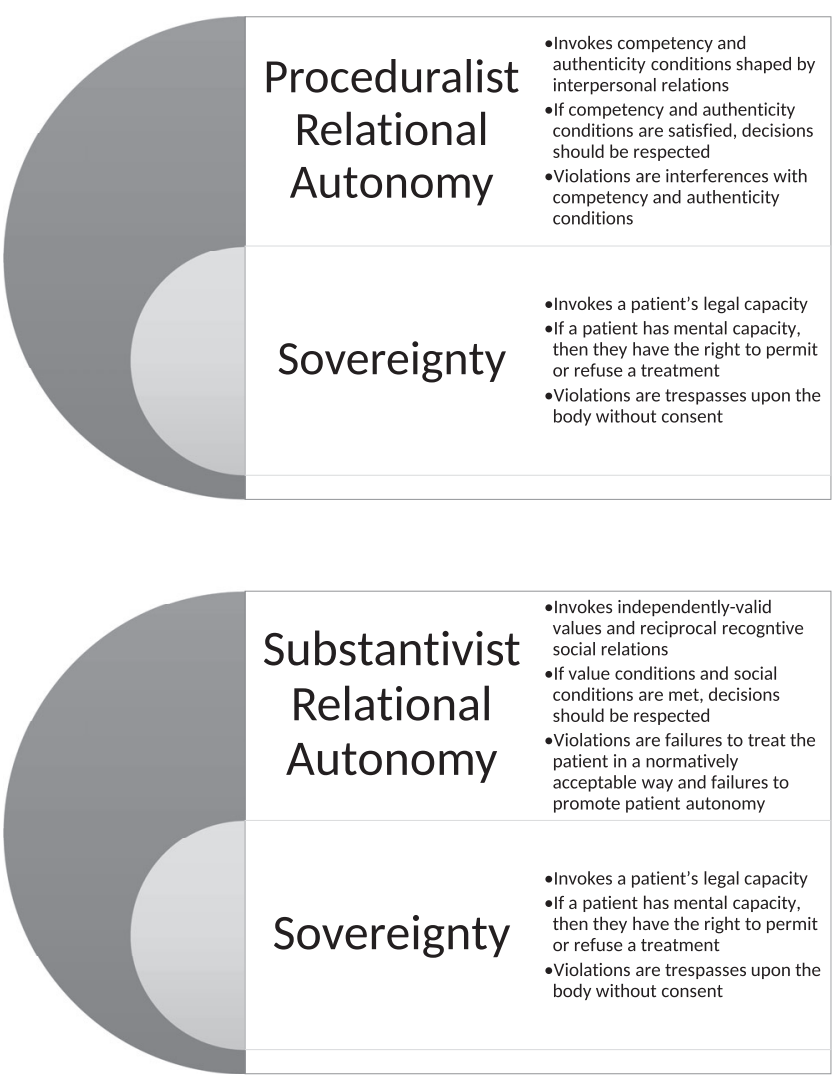

FIGURE 1 Procedural and substantive approaches to relational autonomy and their relationship to sovereignty benefits and potential harms, take into account a patient's values and attitudes, present their recommendations and encourage the patient to communicate their preferences. Despite the fact that there is general consensus regarding the conditions that constitute the decision-making process, there is no agreement about who should make the culminating decision in SDM contexts. For certain proponents, a necessary condition of SDM is a voluntary patient decision. ${ }^{4,14-16}$ A second approach is equally explicit: the decision itself is shared and consists of mutual agreement. ${ }^{1,3,40,41} A$ third approach considers the final decision to be the responsibility of the physician. ${ }^{42}$ Many accounts, however, do not even discuss the question of decisional responsibility. The answer to this question is vital where respect for relational autonomy is concerned.

From a procedural perspective, recognition of a patient's normative authority to make decisions requires a physician to allow the patient to make a decision about what treatment they will or will not receive. In order to recognize a patient's normative authority, a physician cannot manipulate or coerce a patient into making a decision that the physician believes is in the patient's best interests. Consequently, any information that the physician provides should not undermine the authenticity of the patient's decision as a result of either the content of that information or the way it is presented. Furthermore, so long as a patient-according to standard accounts of competency in medical ethics-understands the information provided, retains it, reflects on it, and makes a decision in the light of it, the physician is required to respect that decision even if the patient does not choose wisely. The point is that if a patient's decision is overruled in order to achieve mutual agreement, if it is precluded on the basis that proponents of SDM demand that the culminating decision is the physician's responsibility or if proponents demand that patients should merely communicate informed preferences (without specifically mentioning the patient's right to permit or refuse treatment), then SDM threatens relational autonomy.

As detailed above, respect for relational autonomy cannot be considered separately from autonomy-based considerations regarding patient consent. In order to avoid violations of sovereignty-based legal capacity, the information that needs to be disclosed by the physician is broadly in line with what is required by English law to avoid the tort of battery (p. 394). ${ }^{34}$ Specifically, the supplied or withheld information should not coerce or manipulate the patient. It should not undermine the voluntariness of their decision. Furthermore, the patient must know what the proposed treatments involve in relation to bodily trespass. However, where respect for a patient's sovereignty-based legal capacity is exclusively concerned, the conditions for autonomy do not require a physician to describe the effectiveness, probable benefits, and potential harms of the proposed treatment(s) in order to avoid the tort of battery. For example, in a case where a physician is aware that a patient does not want to continue taking sertraline for their depression, having continuously experienced side effects of diarrhoea, nausea, vomiting, and headaches, SDM would require the physician to disclose information about the side effects of viable alternatives even if the patient has 
not explicitly requested such information. However, the reasons for providing this sort of information cannot be captured by the principle of respect for sovereignty. It has been demonstrated that when it comes to case law, for example, reasons for the disclosure of benefits and harms have been dealt with by the law of negligence rather than battery (pp. 533-535). ${ }^{43}$

The problem is that the disclosure of material risks inherent in a medical intervention or treatment can come at the expense of autonomy as a relational capacity. ${ }^{43}$ If an understanding of benefits and risks is to inform a patient's choice, then, in order to support the competency conditions necessary for the exercise of relational autonomy, it seems that the physician is obliged to provide information regarding the benefits and harms of the available options. However, if a patient suggests that they wish to make a decision based on other values, if they provide reasons for their treatment decision that express these other values or if they ask for details of probable benefits and potential harms to be withheld, then a physician would not be obligated to provide those details even if the absence of such information results in a less informed decision (p. 718). ${ }^{44}$ This may seem problematic to proponents of SDM. For example, in the case of colorectal cancer screening, there are five different options for screening modality as well as the option of no screening. Time wise, a physician cannot provide all possible information on all types of modalities as well as the option of no screening. In order to operate within reasonable time constraints and satisfy what they believe to be in the patient's best interests, the physician might decide to focus the decision on the material risks of the six different options. The point is that whereas proponents of SDM claim that a patient should reflect on the benefits and harms of the proposed treatment options in order to communicate their preferences, the competency conditions for a procedural conception of relational autonomy do not require a generally competent patient to base their decision on the potential harms and purported benefits of the available options. It is up to the patient which values, desires, and motives inform their decision. Consequently, where respect for relational autonomy and sovereignty are exclusively concerned, there is no autonomy-based requirement to provide more than the information needed to avoid violating the law of battery unless the patient asks for such information or the reasons for their preferences indicate that they value such information. If a physician insists on providing information on material risks rather than, or in addition to, the information the competent patient has either requested or valued in the giving of reasons, then, from a purely autonomy perspective, the physician would be interfering with their decision by choosing the information on which the patient should base their decision.

When autonomy is conceived as relational autonomy in a procedural sense, there are specific obligations that are not included in standard accounts of SDM. A failure to fulfil these obligations will, in principle, undermine relational autonomy. Firstly, on the basis that a patient's decisions and the reasons that justify those decisions depend upon, and can only be sustained by, interpersonal recognitive relationships, a patient is required to reflect on, and respond appropriately to, the decisions and reasons given by those who will be affected by the decision. ${ }^{33}$ Certain treatments will require the patient-physician relationship to be expanded to include other individuals, typically, the patient's immediate family. For example, if an elderly patient decides that they want to receive family-led end of life care at home, then they will be required to recognize and respond appropriately to the family's commitments and reasons. To do otherwise would be to disrespect the relational autonomy of their family.

Secondly, as well as providing a patient with viable options and the information necessary to avoid the tort of battery, a physician is obligated to respond to requests for specific information from the patient's family if it is likely to be affected by the decision. Furthermore, respect for the patient's relational autonomy generates a requirement for the physician to reflect on, and respond appropriately to, the family's decisions and reasons. However, this does not mean that a physician has to agree with these commitments just as a physician is not required to agree with the patient's decision (so long as they respect it).

Thirdly, in cases where a patient fails to satisfy the necessary competency and authenticity conditions to exercise their relational autonomy, there is no procedurally conceived, autonomy-based reason for the physician to base their recommendations and decision on the patient's values and preferences. In such circumstances, the physician might just as readily decide to follow the appropriate commitments made, and reasons given, by the patient's family. So long as the physician's commitments and reasons are appropriate and so long as the patient has not fulfilled the necessary procedural conditions, respect for relational autonomy does not generate a requirement for the physician to base their decision on the patient's values and preferences. Furthermore, if a generally competent patient is unable to competently and authentically make a decision about viable treatment options, respect for relational autonomy does not require a physician to promote the patient's relational autonomy. However, as we have already observed, the physician is required to allow the patient to permit or refuse a specific treatment on the grounds of the latter's sovereignty.

\section{I DOES SDM RESPECT SUBSTANTIVE APPROACHES TO RELATIONAL AUTONOMY?}

Catriona Mackenzie argues that there might be good reason to doubt a patient's normative authority to make decisions (pp. 518-519). ${ }^{25}$ For example, illness, internalized oppression, stigmatization, and previous encounters with overly paternalistic or demeaning health care practices can all affect a patient's values and commitments such that respecting their decision would not be consistent with respecting their relational autonomy. The key point for Mackenzie is that if a patient is not recognized as a normative equal in the eyes of those who are holding the patient's decisions to account and if that patient does not recognize themselves as a normative equal in clinical decision-making contexts and broader social situations, then the capacities and recognitive attitudes necessary for autonomy will be undermined 
(pp. 529-530). ${ }^{25}$ For example, as a result of being in an abusive relationship, a patient may not perceive themselves as having the authority to make commitments. In another case, a patient may base their decision solely on what they believe would appease their family rather than on their own values and desires. In short, interpersonal relationships can undermine one's ability to recognize one's normative authority, one's recognition of which values, desires, and motives inform one's commitments and one's ability to recognize one's commitments as meaningful, worthwhile, and valuable. ${ }^{25}$

For Mackenzie, where there is reason to believe that interpersonal relationships and social structures have impaired or undermined a patient's normative authority, "respect for autonomy involves an obligation to promote autonomy" (p. 514). ${ }^{25}$ Such a position is consistent with the approach adopted by proponents of SDM who claim that clinical decision-making processes are meant to promote patient autonomy. ${ }^{414-18}$ It follows that if the promotion of a patient's autonomy is a necessary condition of SDM, then the only conception of autonomy that is applicable to SDM contexts is a substantive one. There is, however, a fundamental conflict between the obligations required to respect relational autonomy and the standards of SDM.

SDM is considered to be an extension of informed consent, one that, nevertheless, does not supersede the obligations of informed consent. ${ }^{1}$ If we refer to sections 2(1) and 3(1) of the Mental Capacity Act 2005, we see that the standards of informed consent operate on the presumption that adult patients have mental capacity and are thereby able to understand, retain, and use relevant information. It follows that SDM operates on the same presumption. By contrast, substantive approaches to relational autonomy do not presume that patients who are of age have the normative authority to make decisions for themselves. In fact, substantivists reverse this assumption. Mackenzie, for example, argues that every decision-making situation "involves an obligation not just to understand but to try to shift [the patient's] perspective and to promote her capacities for autonomy" (p. 528). ${ }^{25}$ Otherwise, decision-making processes would lack "care and sensitivity on the part of the treating healthcare professionals" and "give rise to paternalistic attitudes on the part of medical staff and a sense on the part of patients that they are being coerced" (p. 528). ${ }^{25}$

This reversal of the standard medical decision-making assumption results in a situation whereby the requirements of SDM undermine substantive relational autonomy. Firstly, as we have already seen, standard accounts of SDM require a physician to describe the purported benefits and potential harms of viable treatment options in line with requirements of informed consent. By contrast, if an assessment of a patient's normative authority leads us to doubt that they have the necessary capacity and recognitive attitudes to exercise their relational autonomy, then respect for relational autonomy in itself does not require the physician to describe their material risks. Consequently, unlike SDM, which operates according to statutory requirements of informed consent, there is no corresponding substantive reason for a physician to supply information on material risks unless a patient requests such information having satisfied the substantive conditions needed to genuinely exercise their autonomy. Bearing in mind that respect for autonomy as a relational capacity cannot be considered separately from a patient's sovereignty, all that is required for the physician to avoid violating the tort of battery is to ensure that the supplied or withheld information does not undermine the voluntariness of the patient's decision and to ensure that the patient is aware of what the proposed treatments involve in relation to bodily trespass.

Secondly, whereas proponents of SDM claim that a patient should be encouraged to reflect on the options and the associated benefits and harms so that they can communicate their preferences, respect for a substantive approach to relational autonomy generates this requirement only when the patient wishes to base their decision on these specific details and when their autonomy is deemed to be uncompromized.

Following Mackenzie's argument, if a physician described the purported benefits and potential harms of viable treatment options and insisted a patient communicate their preferences based on these details in line with requirements of standard informed consent based on the statutory presumption that patients of age are competent, then a substantively nonautonomous patient is likely to feel that the physician is being coercive. This further impairs or undermines a patient's normative authority to make decisions for themselves thereby failing to respect their relational autonomy. ${ }^{25}$

Finally, as we observed, the primary concern of substantivists is to promote an individual's relational autonomy rather than merely take account of preferences and respect decisions. In health care contexts, if it is reasonable to doubt a patient's normative authority, then a physician is required to assist the patient with revising their perspective in order to achieve the necessary self-recognitive relationship. ${ }^{25}$ As we saw with procedural approaches to relational autonomy, this obligation generates additional requirements not included in standard accounts of SDM. For example, Mackenzie claims that this shift in perspective involves a physician, family, and friends attempting to counter a sense of personal worthlessness, to promote a sense of self-respect, to assist with finding reasons for living, and to envisage a possible future in which the patient would find a life meaningful (p. 528). ${ }^{25}$ Regardless of the exact means for bringing about such a shift in perspective in a normatively acceptable way, Mackenzie observes that if obligations like these are not enacted by the care team and the patient's wider network of relations, then paternalistic attitudes are likely to arise thereby further impairing the patient's capacity to genuinely exercise their autonomy (p. 528). ${ }^{25}$ If we follow Mackenzie's argument, and on the basis that standard accounts of SDM do not capture these sorts of substantive requirements, SDM, as it tends to be described, operates at the expense of the patient's relational autonomy.

\section{5 | CONCLUSION}

Proponents of SDM have claimed that one of the primary motivations for adopting the practice in clinical contexts is to satisfy the ethical imperative of respecting patient autonomy. One of the challenges facing health practitioners and policymakers is the implementation of an 
account of SDM that is consistent with the principle of respect for patient autonomy. If autonomy is conceived relationally, as proponents of SDM have suggested, then standard accounts of SDM conflict with the obligations generated by the principle of respect for relational autonomy. On the one hand, when we consider autonomy in a procedural sense, the disclosure of material risks, benefits, and harms of treatment options can come at the expense of patient autonomy. On the other, adhering to standard accounts of SDM will, according to substantivists, not only fail to promote patient autonomy, but further undermine or impair a patient's capacity to genuinely exercise their relational autonomy. As well as detailing and justifying these claims, this paper has offered an overview of the kinds of obligations generated by the principle of respect for procedural and substantive relational autonomy that have not been captured by standard accounts of SDM. If SDM is to respect patient autonomy, then it is necessary that proponents revise the requirements of SDM accordingly in order to ensure consistency with the standards of relational autonomy.

\section{ACKNOWLEDGEMENTS}

I would like to thank Ruth Hewitson, Søren Holm, and Tom Walker for their comments and suggestions regarding the paper's principal arguments.

\section{CONFLICT OF INTEREST}

The authors declare no conflict of interest.

\section{ORCID}

Jonathan Lewis (D) https://orcid.org/0000-0001-8342-1051

\section{REFERENCES}

1. Makoul G, Clayman M. An integrative model of shared decision making in medical encounters. Patient Educ Couns. 2006;60(3):301-312. https://doi.org/10.1016/j.pec.2005.06.010

2. Edwards A, Elwyn G. Shared Decision-Making: Achieving Evidence-Based Patient Choice. Oxford: Oxford University Press; 2009.

3. Elwyn G, Laitner S, Coulter A, Walker E, Watson P, Thomson R. Implementing shared decision making in the NHS. BMJ. 2010;34(oct14 2):c5146. https://doi.org/10.1136/bmj.c5146

4. Elwyn G, Frosch D, Thomson R, et al. Shared decision making: a mode for clinical practice. J Gen Inten Med. 2012;27(10):1361-1367. https:// doi.org/10.1007/s11606-012-2077-6

5. Childress JF. Needed: a more rigorous analysis of models of decision making and a richer account of respect for autonomy. Am J Bioeth. 2017;17(11):52-54. https://doi.org/10.1080/15265161.2017.13821 68

6. Christman J. Autonomy in Moral and Political Philosophy. In: Zalta EN, ed. Stanford Encyclopedia of Philosophy 2018 Spring. https://plato. stanford.edu/archives/spr2018/entries/autonomy-moral (accessed 29 November 2018).

7. Beauchamp TL, Childress JF. Principles of Biomedical Ethics. Oxford: Oxford University Press; 2013

8. Dworkin G. The Theory and Practice of Autonomy. Cambridge: Cambridge University Press; 1988.
9. Harris J. Consent and End of Life Decisions. J Med Ethics. 2003;29(1):10-15. https://doi.org/10.1136/jme.29.1.10

10. Schneider C. The Practice of Autonomy: Patients, Doctors and Medical Decisions. Oxford: Oxford University Press; 1998.

11. Dodds S. Choice and Control in Feminist Bioethics. In: Mackenzie C, Stoljar N, eds. Relational Autonomy: Feminist Perspectives on Autonomy, Agency and the Social Self. Oxford: Oxford University Press; 2000: 213-235.

12. O'Neill O. Autonomy and Trust in Bioethics. Cambridge: Cambridge University Press; 2002

13. Walker RL. Medical ethics needs a new view of autonomy. J Med Philos. 2009;33(6):594-608. https://doi.org/10.1093/jmp/jhn033

14. Entwistle V, Carter S, Cribb A, McCaffery K. Supporting patient autonomy: the importance of clinician-patient relationships. J Gen Intern Med. 2010;25(7):741-745. https://doi.org/10.1007/s11606010-1292-2

15. van Nistelrooij I, Visse M, Spekkink A, de Lange J. How shared is shared decision-making? A care-ethical view on the role of partner and family. J Med Ethics. 2017;43(9):637-644. https://doi.org/ 10.1136/medethics-2016-103791

16. Ubel P, Scherr K, Fagerlin A. Empowerment failure: How shortcomings in physician communication unwittingly undermine patient autonomy. Am J Bioeth. 2017;17(11):31-39. https://doi.org/10.1080/15265161. 2017.1378753

17. Dive L. Autonomy, information, and paternalism in clinical communication. Am J Bioeth. 2017;17(11):50-52. https://doi.org/10.1080/ 15265161.2017.1378769

18. Donchin A. Autonomy, interdependence, and assisted suicide: respecting boundaries/crossing lines. Bioethics. 2000;14(3):187-204. https:// doi.org/10.1111/1467-8519.00190

19. Joosten EA, De Fuentes-Merillas L, De Weert GH, Sensky T, Van Der Staak CP, de Jong CA. Systematic review of the effects of shared decision-making on patient satisfaction, treatment adherence and health status. Psychother Psychosom. 2008;77(4):219-226. https://doi. org/10.1159/000126073

20. Stacey D, Légaré $F$, Lewis $K$, et al. Decision aids for people facing health treatment or screening decisions. Cochrane Database Syst Rev. 2017:4: CD001431. https://doi.org/10.1002/14651858.CD001431.pub5

21. Brandom R. Making it Explicit. Cambridge, MA: Harvard University Press; 1994.

22. Brandom R. Reason in Philosophy: Animating Ideas. Cambridge, MA: The Belknap Press of Harvard University Press; 2009.

23. Anderson J. Autonomy and the authority of personal commitments: from internal coherence to social normativity. Philos Explor. 2003;6(2):90-108. https://doi.org/10.1080/10002003058538742

24. Strawson P. Freedom and Responsibility. In: Freedom and Resentment and Other Essays. London: Methuen; 1974:1-25.

25. Mackenzie C. Relational autonomy, normative authority and perfectionism. J Soc Philos. 2008;39(4):512-533. https://doi.org/10.1111/ j.1467-9833.2008.00440.x

26. Sherwin S. No Longer Patient: Feminist Ethics and Health Care. Philadelphia, PA: Temple University Press; 1992.

27. Meyers D (Ed). Feminists Rethink the Self. Boulder, CO: Westview Press; 1997.

28. Mackenzie C, Stoljar N (Eds). Relational Autonomy: Feminist Perspectives on Autonomy, Agency and the Social Self. Oxford: Oxford University Press; 2000.

29. Stoljar N. Feminist Perspectives on Autonomy. In: Zalta EN, ed. Stanford Encyclopedia of Philosophy 2015 Fall. http://plato.stanford. 
edu.dcu.idm.oclc.org/archives/spr2014/entries/feminism-autonomy (accessed December 4, 2018).

30. Stoljar N. Answerability: A Condition of Autonomy or Moral Responsibility (or Both)? In: Hutchison K, Mackenzie C, Oshana M, eds. Social Dimensions of Moral Responsibility. Oxford: Oxford University Press; 2018:231-252.

31. Oshana M. Personal autonomy and society. J Soc Philos. 1998;29(1):81-102. https://doi.org/10.1111/j.1467-9833.1998. tb00098.x

32. Benson P. Feminist intuitions and the normative substance of autonomy. In: Taylor JS, ed. Personal Autonomy: New Essays on Personal Autonomy and its Role in Contemporary Moral Philosophy. Cambridge: Cambridge University Press; 2005:124-142.

33. Christman J. Relational autonomy, liberal individualism and the social constitution of selves. Philos Stud. 2004;117(1/2):143-164. https:// doi.org/10.1023/B:PHIL.0000014532.56866.5c

34. Walker T. Respecting autonomy without disclosing information. Bioethics. 2013;27(7):388-394. https://doi.org/10.1111/j.1467-8519. 2012.01971.x

35. Feinberg J. The Moral Limits of the Criminal Law. In: Harm to Self. Vol.3 Oxford: Oxford University Press; 1986.

36. Archard D. Informed consent: autonomy and self-ownership. J Appl Philos. 2008;25(1):19-34. https://doi.org/10.1111/j.1468-5930.2008. 00394.x

37. Jennings B. Autonomy. In: Steinbock B, ed. The Oxford Handbook of Bioethics. Oxford: Oxford University Press; 2007:72-89.

38. Griffin J. On Human Rights. Oxford: Oxford University Press; 2008.
39. Coggon J. Mental capacity law, autonomy, and best interests: an argument for conceptual and practical clarity in the court of protection. Med Law Rev. 2016;24(3):396-414. https://doi.org/10.1093/medlaw/ fww034

40. Charles C, Gafni A, Whelan T. Decision-making in the physician-patient encounter: revisiting the shared treatment decision-making model. Soc Sci Med. 1999;49(5):651-661. https://doi.org/10.1016/S02779536(99)00145-8

41. Towie A, Godolphin W, Greenhalgh T, Gambrill J. Framework for teaching and learning informed shared decision making. BMJ. 1999;319(7212):766-771. https://doi.org/10.1136/bmj.319. 7212.766

42. Sandman L, Munthe C. Shared decision-making and patient autonomy. Theor Med Bioeth. 2009;30(4):289-310. https://doi.org/10.1007/ s11017-009-9114-4

43. Coggon J, Miola J. Autonomy, liberty, and medical decision-making. Camb Law J. 2011;70(3):523-547. https://doi.org/10.1017/S000819 7311000845

44. Sjöstrand M, Eriksson S, Juth N, et al. Paternalism in the name of autonomy. J Med Philos. 2013;38(6):710-724. https://doi.org/ 10.1093/jmp/jht049

How to cite this article: Lewis J. Does shared decision making respect a patient's relational autonomy? J Eval Clin Pract. 2019;25:1063-1069. https://doi.org/10.1111/jep.13185 